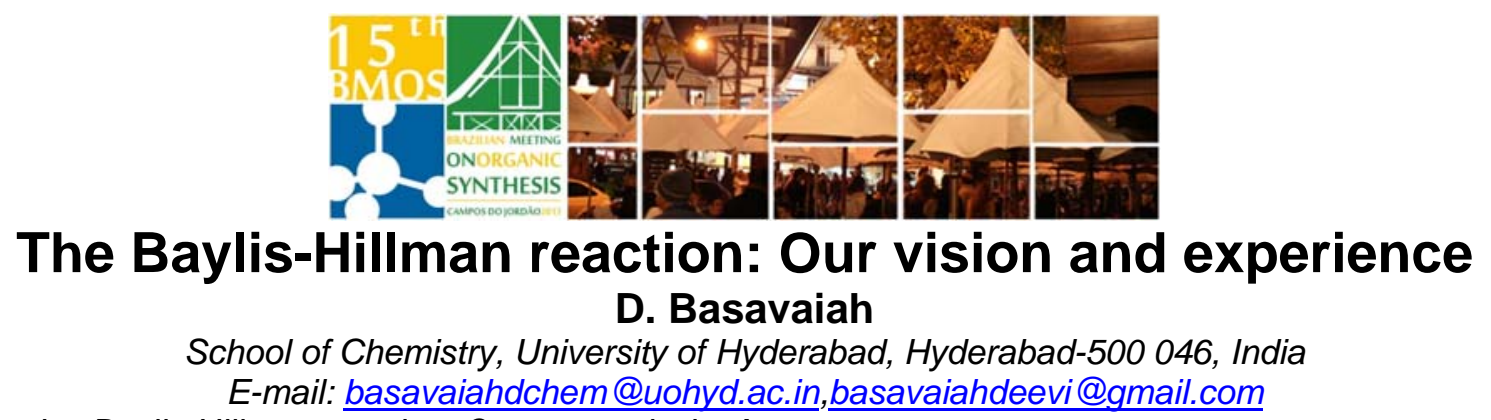

Keywords: Baylis-Hillman reaction, Organocatalysis, Atom economy

\section{Abstract Speech}

To meet the demands of emerging trends, the present day organic chemistry emphasizes the need for discovering new reactions or strategies for construction of carbon-carbon bonds mainly involving the concepts of atom-economy, organocatalysis, and easy generation of useful molecules containing proximal functional groups for assembling the required carbon frameworks. The Baylis-Hillman (also known as the Morita-Baylis-Hillman) reaction is one such organocatalytic atom-economy reaction developed in recent years, for the construction of carbon-carbon bonds leading to the production of diverse classes of molecules having several functional groups in close proximity. It is a three component atom-economy carbon-carbon bond forming reaction between the $\alpha$-position of activated alkenes and electrophiles under the influence of a catalyst (most commonly an organic catalyst). ${ }^{1-8}$ These multi-functional molecules, which are usually known as Baylis-Hillman (BH) adducts, showed enormous utility in many directions of synthetic and mechanistic chemistry, clearly demonstrating the power of proximity of the functional groups in molecules. ${ }^{1-8}$

We have been systematically working on various aspects of this reaction for the last 29 years with the main objective of understanding and developing the Baylis-Hillman reaction as a useful and powerful tool in synthetic chemistry. ${ }^{9-21}$ We have in fact, contributed significantly to its growth with respect to all the three essential components. ${ }^{9-15}$ We have also demonstrated very high applicability and potential of the Baylis-Hillman adducts in a number of organic transformations leading to the synthesis of different carbocyclic and heterocyclic compounds, including bioactive molecules. ${ }^{16-21}$ This talk will present our vision, objectives, and endeavors towards the development of this reaction as a source of opportunities, challenges and creativity in synthetic chemistry keeping its applications as the primary goal.

\section{REFERENCES}

${ }^{1}$ Basavaiah, D.; Sahu, B. C. Chimia 2013, 67, 8.

${ }^{2}$ Wei, Y.; Shi, M. Chem. Rev. 2013, 113, 6659.

${ }^{3}$ Liu, T-Y.; Xie, M.; Chen, Y-C. Chem. Soc. Rev. 2012, 41, 4101.

${ }^{4}$ Basavaiah, D.; Veeraraghavaiah, G. Chem. Soc. Rev. 2012, 41, 68

${ }^{5}$ Basavaiah, D.; Reddy, B. S.; Badsara, S.S. Chem. Rev. 2010,

$110,5447$.

${ }^{6}$ Singh, V.; Batra, S. Tetrahedron 2008, 64, 4511.

${ }^{7}$ Basavaiah, D.; Rao, K. V.; Reddy, R. J. Chem. Soc. Rev. 2007, 36, 1581.

${ }^{8}$ Basavaiah, D.; Rao, A. J.; Satyanarayana, T. Chem. Rev. 2003, $103,811$.

${ }^{9}$ Basavaiah, D.; Roy, S.; Das, U. Tetrahedron, 2010, 66, 5612.

${ }^{10}$ Basavaiah, D.; Sreenivasulu, B.; Rao, A. J. J. Org. Chem. 2003, 68, 5983.

${ }^{11}$ Basavaiah, D.; Rao, A. J. Chem. Commun. 2003, 604.

${ }^{12}$ Basavaiah, D.; Sharada, D. S.; Kumaragurubaran,N.; Reddy, R. M. J. Org. Chem. 2002, 67, 7135.

${ }^{13}$ Basavaiah, D.; Kumaragurubaran, N.; Sharada, D. S Tetrahedron Lett. 2001, 42, 85.

${ }^{14}$ Basavaiah, D.; Gowriswari,V. V. L.; Bharathi, T. K. Tetrahedron Lett. 1987, 28, 4591.

${ }^{15}$ Basavaiah, D.; Gowriswari, V. V. L. Tetrahedron Lett. 1986, 27, 2031.

${ }^{16}$ Basavaiah, D.; Badsara, S. S.; Sahu, B. C. Chem. Eur. J. 2013, 19, 2961.

${ }^{17}$ Basavaiah, D.; Devendar, B.; Aravindu, K.; Veerendhar, A. Chem. Eur. J. 2010, 16, 2031.

${ }^{18}$ Basavaiah, D.; Devendar, B.; Lenin, D. V.; Satyanarayana, T. Synlett 2009, 411.

${ }^{19}$ Basavaiah, D.; Roy, S. Org. Lett. 2008, 10, 1819.

${ }^{20}$ Basavaiah, D.; Reddy, K. R.; Kumaragurubaran, N. Nature Protocols 2007, 2, 2665.

${ }^{21}$ Basavaiah, D.; Satyanarayana, T. Chem. Commun. 2004, 32. 